\title{
Research on Coherence between Secondary and Higher Vocational Educations Based on Vocational Education Group
}

\author{
Nana Shang \\ Foshan Polytechnic \\ Foshan, Guangdong, China
}

\begin{abstract}
Market orientation and serving the economy are purposes of vocational education, the transformation and upgrading of the economy drive that of the vocational education. In order to meet the new development trend, vocational education groups have made a rapid progress, forming a new model of group-oriented schooling and economical development. The coherence between secondary and higher vocational education is an important point for the construction of vocational education system. However, many problems as training goal, specialty setting and curriculum development have arisen in the process of coherence. Starting with the construction of vocational education groups, this article explores new ways to solve the problems so as to perfect the vocational education system.
\end{abstract}

Keywords-coherence between secondary and higher vocational education; vocational education group; vocational education alliance

\section{INTRODUCTION}

The employment-oriented vocational education must be in front of economic development in order to foster technical and skilled talents and meet market demands so as to ensure the quality of students in employment. The economic transformation and upgrading in China calls for the transformation and upgrading of vocational education, it is a must for the coherence between secondary and vocational educations (hereinafter called the two educations), an important part in the vocational education system, to face challenges by the economic transformation and development upgraded in China. In order to better meet the requirements of economic development in talents and the urgent need for further studies by students in schools of secondary vocational education, the coherence between the two educations must be upgraded in all aspects.

In the face of social and economic challenges, the vocational education has gradually formed a cross-border coordination including collection of multi-party forces, integration of stakeholders' resources in vocational education, establishment of vocational education group, group-based school running and socialized operation. The problems arising in the coherence of the two educations should be solved with a new perspective in order to meet the demands of social development. Therefore, it needs to explore new ways to solve the problems existing in the construction of coherence of the two educations from the advantageous resources in the school running by vocational education groups, break up the boundary of the two educations so as to really achieve the coherence and improve the modern vocational education system.

\section{Problems Existing In the CoHERENCE OF THE Two EDUCATIONS}

In different periods the economic development has different requirements in the vocational education. In the early stage of liberation, the talents from the secondary vocational education could meet the needs of economic development of that time to a large extent and serve the local economies. However, with the development of the economy, higher and higher requirements are raised, yet the secondary vocational education is unable to meet the needs of the time, thus it comes to a channel through which students from the secondary vocational education are admitted to the higher vocational education. Due to the historical gap between the two educations, there are many problems encountered in the construction of coherence of the two educations.

\section{A. Unclear Training Goals}

The two educations are designed at different levels in the vocational education system, then the training goals of the two should also be different but similar in some degree. However, at present, the unclear orientation of the two education on the training goals make it difficult to achieve the coherence of the two educations.

The dislocation of training goals between secondary vocational schools and higher vocational colleges has reduced the attraction of vocational education. The Opinions of Promoting Overall Quality Education and Deepening the Reform of Secondary Vocational Education and Teaching released by the Ministry of Education points out, the secondary vocational education should fully implement the Party's education policies, change educational thought, establish an overall quality and ability-based new idea, train high quality laborers, medium and junior specialized talents who are adapted to the construction of socialist modernization, allaround development in moral, intelligence and PE and fine arts, 
owing comprehensive vocational skills in the production, service, technology and management. The "Several Opinions on Overall Improving the Quality of Higher Vocational Education and Teaching" pointes out, the higher vocational education, a type of higher education in development, shoulder the mission to foster highly-skilled talents for the production, construction, service and management, and it has an irreplaceable role in the country to accelerate the construction of socialist modernization. Therefore, training goals of secondary vocational education are to foster high quality laborers and medium and junior specialized talents, and different schools will vary in the understanding of medium and junior specialized talents. The schools with mature conditions have continuously raised standards for talent training, which even reaches the requirements of higher vocational education. But for general secondary vocational schools, to complete the secondary vocational education has been the result by efforts of all parties. For the training goals different in the secondary vocational education, it is even harder to well grasp the training goals of higher vocational education. Highly-skilled talents are training goals of higher vocational education, yet the understanding in how to define the highly-skilled talents also differs. If the training goal of higher vocational education is lower, its attraction to the students from the secondary vocational schools will be reduced, and it will result in a waste of resources. If the training goal of higher vocational education is higher, it will frustrate the enthusiasm of the students from the secondary vocational schools, resulting in the loss of student sources. Facing the imbalance between the two educations, the unclear training goals between the two will make it much more complicated.

\section{B. Improper Specialty Setting}

Vocational education shall serve the local economies, relying on characteristics of regional industries to set a featured specialty is an advantage in the vocational education. Vocational schools have greater autonomy in setting specialties, which bring a major test to colleges and universities in the connection of specialty with the two educations, and the improper specialty settings will inevitably affect the quality of cohesion of the two.

Seen from the secondary vocational education, the complexity of secondary vocational schools will inevitably cause the complexity of specialty settings. At present, the secondary vocational education in China comprises vocational high school, secondary vocational school and technical school, the schooling type of the three differs with tech other. The vocational high school has functions of high school and vocational school, the specialty setting there varies with that in secondary vocational school. Technical school and secondary vocational school are at the same level in the vocational education, yet the secondary vocational school is administrated by the Ministry of education, the technical school is administrated by the Labor Bureau, different administrative departments have different emphasis in the specialty setting. In the specialty setting, the higher vocational colleges highlight the characteristics of serving the local economic development, and the specialty setting is based on the economic development. Sometimes, it will be difficult for the secondary vocational education to find a "connection point" in the higher vocational education, and the improper specialty setting will be a barrier for the construction of the vocational education system.

\section{Inconsistent Courses}

The course is a guarantee for the quality of education and a key part in the vocational education, yet the insistent courses between the two educations has influenced the rapid and healthy development of the vocational education. The course setting varies with school-running conditions, as for as the secondary vocational education, the course setting in some secondary vocational schools have covered that in higher vocational colleges, yet the course setting in some higher vocational colleges has fallen behind the secondary vocational schools. The insistent or overlapped courses have caused a waste of course resources, and also brought puzzles to students. During the development of school/college based courses, it will be a key to solve the course coherence between the two educations through its integration to the development process.

\section{A VocATIONAL EDUCATION GROUP-BASED NEW BREAK-THROUGH FOR THE COHERENCE OF THE TWO EDUCATIONS}

The coherence between the two educations is the need of economic development in China, in order to adapt to the upgraded economic development in China, it needs to create an upgraded coherence between the two educations. The plight in the construction of the coherence of between the two educations is a key for the construction of and the point to break through for the upgraded coherence of the same. The group-based school running is a school running mode through multiple cooperation, which takes the vocational education group as the base for organization, and the perfection of vocational education production-study cooperation mechanism as a means, the close relations between politics, administration, school and enterprise, the deepening of mutual cooperation as a way, and the improvement of teaching level, quality of talent training and social service capabilities as goals, and it is a school running behavior which are involved in the most factors and the most complicated relations during the development of vocational education in the country. [1]Though the groupbased school running makes a rapid progress across the country, yet there is still no a uniform system, whose names differ with each other, and the vocational education group consists of various modes as vocational education alliance, vocational education group, cooperated education community and the like. For the vocational education groups are involved in a large number of stakeholders, within the vocational education groups, all stakeholders will be united to solve the problems encountered in the coherence of the two educations, break through the inhabitation where problems are solved traditionally in the system of schools, and achieve the crossborder innovation for the coherence of the two.

\section{A. Take the Vocational Education Alliance As A Platform and Clarify Training Goals of the Two Educations}

Training goal is a talent training plan of schools of all types and levels according to school types and levels so as to meet 
the needs of all industries and trainees. Vocational education and economic development are closely related, the schoolenterprise cooperation cannot be separable from the participation of industries and enterprises, in order to foster talents needed by the society, the establishment of training goals of the two educations must have the participation of enterprises, both schools and enterprises work together to achieve the seamless connection of talents. The vocational education alliance is a favorable platform where enterprises and schools, as well as schools and schools are integrated, where resource sharing and mutual complements in advantages. The establishment of training goals of the two educations shall, relying on the vocational education alliance, shall be established by secondary vocational school, higher vocational college and enterprises outside so as to achieve the efficient connection of training goals.

The vocational education alliance is an important platform for dialogues between the two educations, without the heartfelt dialogues, there will be no real connection. Within the vocational education alliance, secondary vocational education schools and higher vocational education colleges may understand the enterprises' demands for talents in time, establish standards for talents quality as per the enterprises' requirements in talents, and achieve the seamless connection of the two in the vocational education. The two educations belong to the same type of vocational education, but different in the level, therefore, the training goals have common features and differences. For example, the training goals of the two educations have features as practical, operational, professional, social and so on. However, the two educations differ in the level, the higher vocational education, an important of higher education, must have high levels in training goals. So in order to well adjust the relations between the two educations and further make coherence of the two, first of all, it must be classified otherwise it will be hard for positioning and to achieve the coherence in specialty, course and teaching contents. In order for the classification, the industrial enterprises should classify various occupations, vocational colleges shall convert the occupational classification, which will be learned by students. In order to protect the effective coherence of training goals of the two educations, a vocational education alliance is established in Sanshui District, Foshan City. The first board of management comprises 71 member units, including five vocational schools in the governed area; 4 associations and chambers of commerce; 62 enterprises. The board of management has invited 11 units as district education bureau, district economic promotion bureau, district human resources and social security bureau, district federation of trade unions and towns (sub-district offices) governments. The establishment of the vocational education alliance embodies the openness and popularization of vocational education, avoiding the blindness and closure of the the two educations in the establishment of training goals.

\section{B. Take the Vocational Group As the Center, Coordinate the Specialty Setting}

Specialty and vocational posts are closely related, the specialty setting is an important manifestation of characteristics of school running, the specialty setting in the two educations differ with that in general education, which is renewed with the changes of market economy, and the renewal speed is faster than that of general education. In order to solve the problems of specialty setting in vocational education, the Several Opinions of Accelerating the Vocational Education Group-based School Running released by the Ministry of Education points out, "Actively explore and promote resource integration, restructuring and sharing in vocational schools; take specialty and industry as a tie, the backbone vocational schools as cores, relevant vocational colleges as members, cooperate with industries, enterprises, institutions and other relevant organizations to form various vocational education groups, further promote the combination of industry-study, school-enterprise cooperation, internship; strengthen regional cooperation and urban-rural cooperation; achieve the resources sharing complement in advantages and co-development between schools, business, industries and regions." The vocational education group is the center to study the specialty setting in the two educations, and a breakthrough for the specialty setting.

The market-oriented specificity of vocational education has caused poor standards and normative in the construction and development of specialties from secondary vocational schools to higher vocational colleges, and it is random in the specialty classification, specialty requirements and names, which results in the difficulty to coordinate specialties for the two educations. The specialty coordination herein is not the one-to-one correspondence in specialty setting between the two educations, and it is unnecessary to secondary vocational schools to find a connection point in specialty setting, for some posts will not require high level talents, which may take the posts after completing the secondary vocational education, such as service, the post with higher requirements in operation may be not set in the higher vocational education, and there is no so called connection between the two educations. [3] Common requirements of the two educations in specialty setting: set specialties as per the actual needs of areas and industries, but not copy the mode of general higher education. One of the common trends in educational reform worldwide is to broaden the specialty scope and enhance the adaptability of graduates' employment, which is a basic principle of the secondary vocational and higher vocational education. [4] The vocational education groups take specialties and industries as ties, highlight characteristics of industries, develop a servicebased specialty group through which, the two educations may set specialties, achieve the flow of knowledge and skills within the group, and coordinate the specialty setting in the two educations.

\section{Take Vocational Capabilities As Support and Make It Go through Courses in the Two Educations}

Curriculum of vocational education originates from occupations, and skills needed by the occupations are extracted out of the work to establish occupational competence standards, and which will then be converted to the learning, and the curriculum will be developed after discussion and improvement by relevant experts. The development of curriculums should be based on the laws of vocational education, which will be achieved by specialized personnel 
under certain procedures. At present, the course settings in secondary vocational schools and higher vocational colleges are complex, and different standards make it difficult for the coherence of courses of the two, main reasons are that the occupational competence standards have not yet been established or perfected. In order to realize the coherence between the two, it shall not only be kept well going through the school running entities but also through the schooling connotation, where the course is a core for the construction of connotation.

The essence of the coherence of courses between the two educations is not to highlight the high level of the higher vocational education over the secondary vocational education in curriculum, and not to press down the secondary vocational education, but to make the curriculum be related between the two. [5] According to the "Principle of Readiness", it can be said that the secondary vocational education is a necessary preparation for the higher vocational education, and the higher vocational education is a continuation and upgrading of the secondary vocational education. With the lack of secondary vocational education, the higher vocational education is incomplete, which can only be higher in cultural theories, but medium in professional skills; meanwhile, with the lack of the higher vocational traction, the secondary vocation education is suspended, in the lack of attraction. [6] Vocational competence standards are main lines throughout the curriculums of the two educations, in order to solve the difficulties encountered in the coherence of the two educations, it needs establish vocational competence standards. The industries, enterprises, secondary vocational schools, higher vocational colleges and relevant experts shall cooperate to develop vocational standards, which is the highest priority in the construction of courses of the two educations. Different levels of vocational competence standards correspond to the different levels of vocational education, a pyramid-like vocational competence standard shall be base for the coherence of curriculum in the two educations. Therefore, both of the development of curriculum in the two educations should have the participations of industrial enterprises, secondary vocational schools, higher vocational colleges and relevant experts.

\section{CONCLUSION}

The coherence between the two educations is an important part for the construction of vocational education system, and also the key for the construction of vocational education connotation, especially the foundation for the upgrading of vocational education. Rely on the collective strength of vocational education groups, face the problems in the coherence of the two educations, deeply analyze stakeholders involved in the problems, coordinate the interests of all parties through the platform of vocational education group, make the beneficiaries of vocational education undertake duties and share costs of the vocational education in order to fundamentally solve the problems, and it is a drive for the sustainable development of vocational education, meeting the transformation requirements needed for the development of modern economy.

\section{REFERENCES}

[1] Shen Mingzhong, Xu Zhenzhen Group-Based School Running in Vocational Education: Influencing Factors and Countermeasures [J]. Vocational \& Technical Education Forum, 2016(25):32-35

[2] Guo Dongsheng, Discussion on the Coherence between Secondary and Higher Vocational Educations in China [J]. Vocational \& Technical Education Forum, 2009(9): 16-19

[3] Xing Hui, Discussion on the Coherence between Secondary and Higher Vocational Education - analysis of Reform of Enrollment Exam System of Higher Vocational Education [J]. Educational Science Research, 2000(1):27-33

[4] Same as [2]

[5] Xu Guoqing, Shi Weiping, Discussion on Curriculums for Coherence between Secondary and Higher Vocational Educations [J]. Educational Research, 2012(5):69-73

[6] Liu Chunsheng, Zhang Cunqun, Discussion on Theoretical Basis for Coherence between Secondary and Higher Vocational Educations [J]. Vocational and Technical Education, 2000(19):4-8. 